\title{
The Impact of Human Resource Development (HRD) Practices on Organizational Effectiveness: A Review
}

\author{
Md. Bashir Uddin ${ }^{1}, K_{\text {Kamrun Naher }}^{2}$, Afroza Bulbul ${ }^{3 *}$, Neser Ahmad ${ }^{4}$, Mohammad Mizanur Rahman $^{5}$ \\ ${ }^{1}$ Assistant Professor, Department of Business Administration, Sylhet International University, Sylhet, BANGLADESH \\ ${ }^{2,4}$ Senior Lecturer, Department of Business Administration, Sylhet International University, Sylhet, BANGLADESH \\ ${ }^{3}$ Associate Professor, Department of Business Administration, International Islamic University Chittagong, Chittagong, BANGLADESH \\ ${ }^{5} \mathrm{Ph} . \mathrm{D}$ Student, Department of Management and Marketing, Univesiti Putra Malaysia (UPM), MALAYSIA \\ *E-mail for correspondence: afrozabulbul132@gmail.com
}

DOI: https://doi.org/10.18034/abr.v6i3.38

\begin{abstract}
This paper attempted to review theoretically the HRD and its matrix and revealed to show the positive relationship between HRD and organizational effectiveness. In HRD shows the different variables (outcomes) such as HRD instruments, HRD processes \& climate variables and organizational dimensions. HRD affects the organizational goals which may result from higher productivity, cost reduction, more profits, better image and more satisfied customers and stake holders considered as organization dimensions HRD activities, as such, do not reduce costs, improve quality or quantity, or benefit the enterprise in any way. It is the on-the- job applications of learning that ultimately can reduce costs, improve quality, and so forth. In the organizational context, therefore, HRD means a process which helps employees of an organization to improve their functional capabilities for their present and future roles, to develop their general capabilities, to harness their inner potentialities both for their self and organizational development and, to develop organizational culture to sustain harmonious superior-subordinate relationships, teamwork, motivation, quality and a sense of belongingness. The study also analyses the Kliman Model of HRM to show the path of mechanisms which could lead to competitive advantage. Today's fast changing environment modern organizations are more careful to sustain in the competitive advantage relating to HRD our study has been developed to help the management students, academicians, and professionals to understand the subject properly and enhance their knowledge about HRD network within the organization for its effectiveness.
\end{abstract}

Keywords: HRD, Training \& Development, HRD Instruments, Organizational Effectiveness

\section{INTRODUCTION}

HRD is concerned with an organized series of learning activities, within a specified time limit, designed to produce behavioral change in the learner. In the opinion of Nadler the term "HRD" was first applied in 1968 in George Washington University. It was used in Miami at the conference of American Society for Training and Development (ASTD) in 1969. According to Nadler (1980), the term was gaining more acceptances during the mid-1970, but many used it as a more alternative term than "Training \& Development."In the opinion of some management professionals, Japan is the first country to begin with HRD practices. "Better People," not merely better technology, is the surest way to a "Better Society," is the most popular belief in Japan (Basu, 1987).
This study explains the HRD mechanisms, HRD culture, HRD climate, role of HRD units, HRD Matrix, HRM philosophy, etc. to go for organizational effectiveness.

\section{Statement of the Problem}

There may be certain inadequacies in the study which create roadblocks and prohibit the organizations from being effective. Here the meaningful role of HR professionals comes in. We expect to remove these inadequacies while formulating the strategies and designing HR interventions as times moves on. It is the practice of enhancing the enabling capacity of individuals, collectives, and organizations through the development and application of learning based interventions for the purpose of optimizing employees and organizational growth. 


\section{Importance of the Study}

Research, experimentation, and experience in the field of HRD have grown enormously in the last decade. Our study has been done to show remarkable work in attempting to find out new ways of developing employee competencies. Thus, HRD is needed by every organization that is interested in stability and growth with the dynamic activity that may result from effectiveness and corporate leadership in competitive advantage.

\section{Sources of Data}

The study has been done by secondary sources like different journals, published articles, books and websites, etc. This is a theoretical analysis of nature.

\section{LITERATURE REVIEW}

Human resource management is a chastisement, an expert specialization that has created in late years as an expansive range, enveloping different field consolidated and union with certain component of work force administration hierarchical conduct modern and work relationship and so forth As indicated by Susan (2005), Human resource management is the capacity inside an association that spotlights on enlistment of, administration of and giving course to the individuals who work in the association. Human Resource administration can likewise be performed by line administrator. Human resource administration is the authoritative capacity that arrangements with issues identified with individuals, for example, remuneration, employing, performance management, association advancement, wellbeing, health, benefits, worker inspiration communication, administration and training (Susan, 2012). Human resource management is additionally key and extensive way to deal with overseeing individuals and the work place, culture and environment. Viable Human resource management empowers representatives to contribute viably and beneficially the generally speaking organization heading and the achievement of the association's objective and targets (Susan, 2012).

Mangers dealing with people at work have generally an inferior position in company hierarchy. Although the basic function of personnel department is to attract, develop, and retain the right kind of people for the right kind of job, so as to achieve effective development and utilization of manpower, personnel department in Bangladesh is indeed fighting to deal with adversarial relations with employees. This is why; many scholars and practitioners have given their attention on how to develop HR through human resource department (HRD) which may result organizational effectiveness. Some of the following writings/ studies have been considered as reviewed earlier.

Rao, a pioneer of HRD, (1999) defines human resource development (HRD) as essentially consisting of three Cs:competencies, commitment, and culture. All three are needed to make an organization function well. He explained that without competencies organizations cannot ensure efficiency. Without commitment organization faces slow pace growth. Culture supports the organization to live long-time as oxygen. It has been rightly observed by Billimoria \& Singh (1985) that "each human being is born as something new, something that never existed before. Each is born with the capacity to win in life, each has his own unique potentials, capabilities and limitations". Here, they added that organization should come forward to nurturing human resources. HRD is an approach founded on the belief that people are capable of growth - given an environment that facilitates individual growth (Dayal, 1993). Growth is, therefore, important for organization. According to Dayal, HRD is to make a person, a total person in terms of skill, maturity, competence, selfawareness, adjustment to the environment, and confidence. In the view of Dayal, HRD can be seen as a philosophy rather than as a programed. HRD is concerned with two sets of extreme factors - which prevents growth and which leads to growth. In this context Khan (1987) also remarks: "HRD is the process of increasing knowledge, skills, capabilities and positive work attitude and value of all people working at all levels in a business undertaking". Sharif (1999) mentioned in his article that empirically verifies the contributions of the 'HRD' efforts in the growth process of an economy. From this paper, the role of HDR has been noticed very strong as well as necessary stimulating the growth voyage of an economy like Singapore continually. He considered people as 'Human Capital and 'knowledge'. The need for investment in the human resource development is positively correlated with the rate of technological progress (Chowdhury, 2003). He explained that higher rates of growth can be achieved by adopting sophisticated techniques due to increase in the scale of production and operational complexity, the demand for highly qualified specialists and administrators also increase in the corporate world. Chowdhury (2003) reviewed that the workers come in various forms from skilled to unskilled, professional to illiterate and old to young. Placing a worker in a job is only the first step in HRD. Today's fast changing world of corporate practices also requires the human worker, say in an organization, to be coached irrespective of his level of skill. He also said that human resource development has been described as a journey towards higher level of performance. An important element of this journey is training which shyness to invest in the future is. Ahmed, et al. (1993) attempted to highlight the strategies for human resource development adopted so far in Bangladesh, achievement in this respect and in view of gradual industrial restructuring and potential areas of labor absorption, suggest some measures for obviating the imbalance which exists between demand for and supply of labor force in the job market of the country. Rao, et al. (1988) mentioned in his book that people in the organization are helped to acquire new competence so as 
to make confident them with sensitivity. They emphasized HRs to cope with the changes. Sharmaand and Purang (2000) surveyed of 27 middle level managers in the engineering sector, manufacturing primarily power sector equipment with a view to understanding relationship between value institutionalization and HRD climate. The study highlights that there exists positive relationship between value institutionalization and HRD climate.

From the above citations of the literature regarding the application of HRD along with HRD Matrix in job of the business organizations our study tries to show how it ultimately can reduce costs, improve quality, productivity and higher profits which may result organizational effectiveness (outcome).

\section{ObJectives of The Study}

The main objective of the study is to organize long-term organizational effectiveness (outcome) through HRD. In the study, keeping in view aforesaid discussion above, the following objectives have been laid down:

- To develop capabilities of all individuals working in an organization about their present and future roles;

- To develop HRD mechanisms lead to the desired outcomes;

- To ensure efficiency through HRD instruments;

- To link HRD with organizational strategy;

- To find out the inadequacies in the HRD practices and provide broad guidelines to keeping pace with the technological changes and suggestions for enhancing organizational effectiveness.

\section{Discussion}

\section{Functions/ Activities of HRD}

HRD covers all HRM functions. To attain the aforementioned objectives HRD unit performs the following functions by applying the HRD instruments or interventions:

- Human Resource Planning (HRP): By jobs demand HRD unit tries to establish HRP by which HRD the manager needs to be able to forecast what the organization's future HR requirements will be and from where the HR will be obtained. If HR is surplus, the manager gives an attention retrenchment strategies or stopping recruitment so that organizations minimize their costs. If shortage, manager starts recruiting and accelerating training and development.

- Recruitment and selection: HRD attracts HR from internal and external sources and selects the qualified candidates from a huge number of applicants.

- Performance and Potential Appraisal: Performance appraisal means an evaluation of individual doing. They are well known to what should be done by themselves if needed. HRD manager helps employees in self-appraisal or peers or 360-degree feedback. Potential appraisal is done for placement as well as for development purposes keeping in mind futuristic requirement of the organization.

- Counseling: HRD supports to give critical feedback and discusses them how they can improve themselves.

- Career Planning: Career planning involves identifying the right potential well in time, for development to take over higher responsibilities. HRD tries to establish a promotional policy for people.

- Succession Planning: HRD makes succession planning for those who are fit/ right for the next position so that organization cannot trap in operations.

- Training: Training comprises an integral part of HRD process. To increase employees' efficiency and effectiveness on the job, HRD tries to improve the capabilities of HRs through arranging the different types of training programs.

- Job Evaluation: How much should be paid for a job which ensures by HRD through job analysis regarding the responsibilities of the job.

- Transfer, Promotion \& Demotion: A transfer may result in changes in duties and responsibilities, supervisory and working conditions, but not necessarily salary. On the other hand, promotion is the advance position of an employee from one job to a higher level one, with increase salary. Whereas, demotion is the opposite of promotion that creates the downward position. HRD manager ensures those who are the right person for the right position in an organization.

- Role Analysis: For the requirement of effective role HRD elaborates the processes, standards, and critical attributes namely knowledge, attitude, skills habits (KASH) which in turn in the context of its works system.

- Communication Policies: HR Department stresses a lot of communication aspects to be developed that do pave the way for effectiveness and efficiency.

- Rewards: Rewards are the positive reinforcements given by the organization which act as effective motivators and help people to increase productivity and efficiency such as promotion, reviewed salary, fringe benefits, etc.

- Organizational Development (OD) Exercises: OD exercises help organization in the development and growth with their activities of an organizational diagnosis, team building, task force, other structural and process interventions like role development, job enrichment, job re-designing, etc.

HRM functions are the best tools to achieve the same which result organizational outcomes may act as creation of image, more profits, higher productivity, more competent people, more team work and finally ensures better utilization of human resources (see fig-4).

At this stage, for better appreciation, we would mention the HRD objectives of two leading companies: 


\section{EXHIBIT-1}

\section{HRD Objectives of Siemens Limited}

Main objectives of Siemens are:

- Development of employees is the primary task of the company;

- It is the policy of Siemens to recruit, train, develop and advance employees within the company;

To achieve these objectives Siemens have laid down their policies as under:

- Recruitment of quality manpower and their retention;

- Plan and monitor career development staff to perform effectively in their present jobs; groom potential managers for higher responsibilities;

- To introduce and sustain an objective system of evaluation of performance based on result;

- Performance as the sole criterion for increments and promotion;

- Use of training as the strategic factor for competitive advantage;

- To nurture a spirit of entrepreneurship among employees;

- Work in close collaboration for fostering the spirit of openness;

- To ensure transparency in decision making:

-Self-motivated employee

-Employee commitment

-Commitment of results.

\section{EXHIBIT-2}

\section{HRD Objectives of W.S. Industries India Limited}

- To plan and induct appropriate manpower regarding of knowledge, skills, and attitude (KSA);

- To provide opportunities for growth to employees regarding of remuneration, career and skill endowment.

- To practice equity and fairness in all its dealing with employees;

- To continuously enhance knowledge, skill of employees for the performance of their present and future tasks through education and training;

- To create an organizational climate which encourages a highly motivated workforce;

- To prepare employees for easy and faster adaptation to change.

From the above, it is clear to us that the two companies' HRD objectives and HRM practices are almost same and their retention/ maintenance factors are in practice so that the existent employees cannot switch other organizations and they are committed to contributing organizational development.

\section{RESPONSIBILITY OF HRD}

HRD is thus the responsibility of both: line managers and HRD /Personnel specialists. It is a co-operative and massive effort in the organization. Rao and Pareek (1981) observed that there are six units in an organization which are concerned with HRD. These are: - (i) person; (ii) role; (iii) dyad; (iv) team; (v) inter-team \& (vi) organization. The effectiveness of one unit (foci) will contribute to the effectiveness of others. The holders of a variety of positions in the sub-departments report to top person (head of HR Department). Those reporting to the head of the HR Department typically include:

- Manager of employment (responsible for HR planning, recruitment, selection and performance appraisal).

- Manager of compensation (responsible for compensation, incentives and benefits administration)

- Manager of training and development Responsible for Orientation, Training, Development and career planning).

- Manager of health and safety (responsible for occupational health and safety administration).

\section{STRUCTURE OF HRD SYSTEM}

Different organizations have different types of organizational plan which really depends on the size, nature, functions and vision of an organization. Rao, Raju, and Yadav (2001) surveyed HRD practices in 12 Indian organizations covering financial services, consumer products, electronics, cement, tyres and automobiles which shows that employees perceived as favorable the value of autonomy. Here precise HRD structure has been shown hypothetically of different types of organization as follows.

Fig. 1: Organization Chart No. 1- For a Large Company

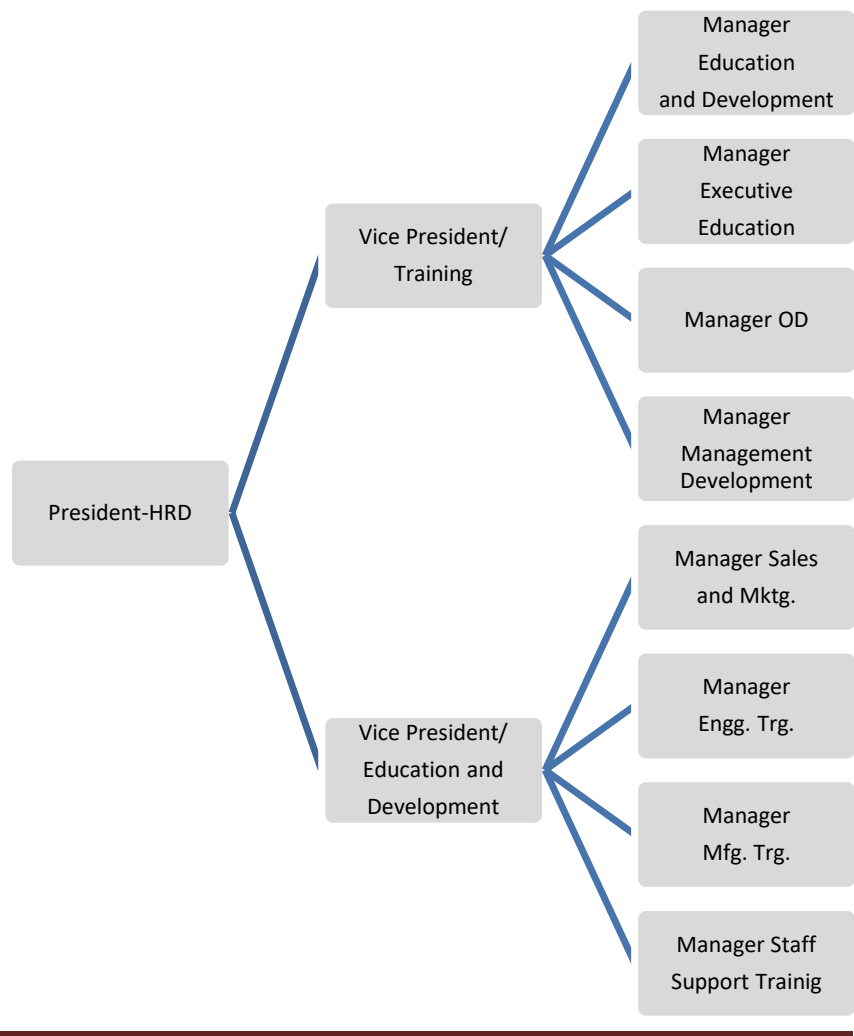


Fig. 2: Organization Chart No. 2- Integrated HRD

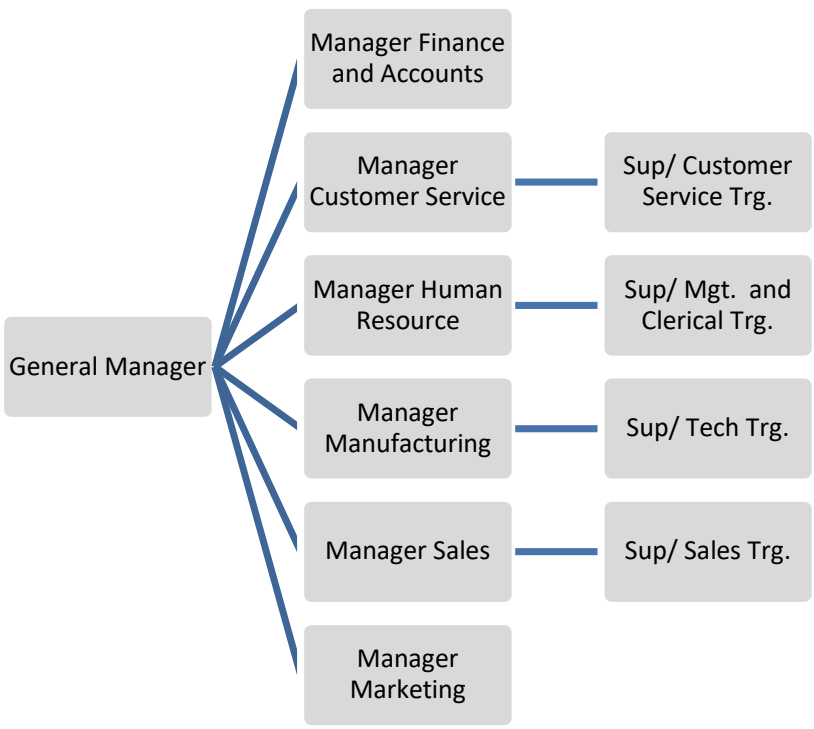

Fig. 3: Organization Chart No. 3 - HRD as a Separate Department

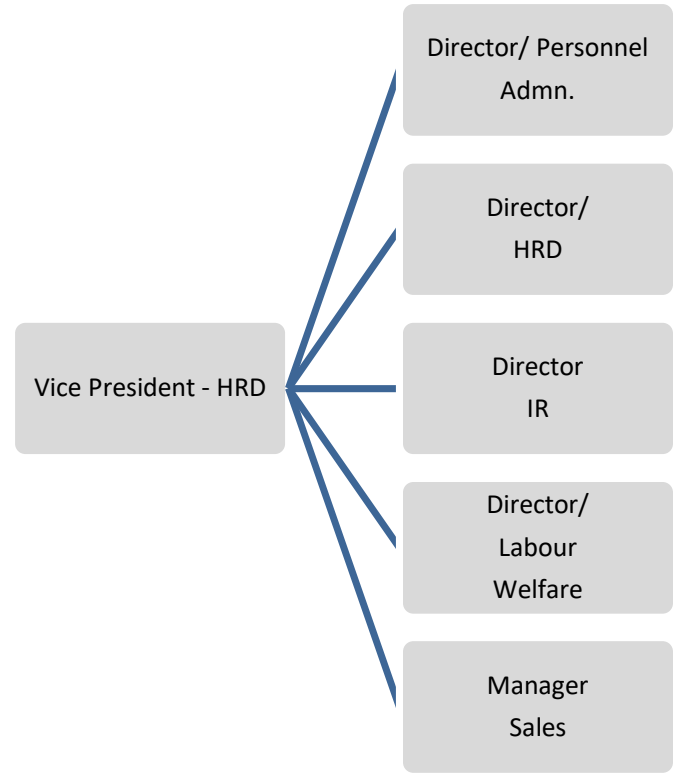

It appears that the structure of HRD department varies from organization to organization in terms of size, nature of activity, philosophy and attitude. And this shows it as a separate functional identity in an organization.

\section{HRD CULTURE}

In a changing environment, organizations are required to go for frequent restructuring and re-designing of activities. HRD culture enable the organization to adopt with the rapid changes which is characterized by openness, confrontation, trust, autonomy, pro-activeness, authenticity, collaboration practices.

\section{HRD CLIMATE}

To understand the HRD climate, organizations often institute some structured questionnaires for finding out the gap and take remedial measures. Some of the questionnaires, could be as - (i) Does the organization consider employees as the most important resource? (ii) Does the organization believe in developing competencies of all cross-sections of employees and initiate action in that direction? (iii) To what extend the organization is transparent in communication? (iv) Are the employees encouraged to take risks? (v) Is there a climate of collaboration, team spirit, mutual trust and confidence? (vii) To what extend are HRD activities development oriented? Over these questionnaires, organization could be able to find out the deviation between goals and obtained results and take remedial actions.

HRD INTERVENTIONS/ SUBSYSTEMS/ MECHANISMS According to Rao, major interventions of HRD are (i) Performance and potential appraisal; (ii) Career Planning; (iii) Training; (iv) Organization development; \& (v) Reinforcement. HRD interventions may vary from one organization to another depending upon their needs, based on diagnostic studies.

\section{HRD STRATEGY}

HRD integrates $\mathrm{T}$ \& $\mathrm{D}$, organizational development, (OD), career development etc. due to improving individual, group and organizational effectiveness. Many professionals feel that if only HRD could be effectively linked to the organizations' long-term strategy, then it would command top management's attention, galvanize, management support, and attract additional resources. HRD strategies believe that in order to involve employee to be successful that team effectiveness training should be delivered internally. It provides training client personnel to learn the skills required to facilitate the team effectiveness training systems. For instance, The BIG (The Big Lottery Fund) competency framework, develop in partnership with SHL, has been fully integrated into recruitment, appraisal and employee development. This ensures that HR is aligning its processes to business needs and developing a framework to develop employee capability and management effectiveness.

\section{HRD MATRIX}

HRD Matrix is the interrelationship between HRD practices and organizational effectiveness (Bhattacharyya, 2006). HRD practices generate HRD processes, which result in HRD outcomes that contribute to organizational effectiveness. Rao (1990) developed such a matrix which is presented below: 
Fig. 4: A Schematic Presentation of Linkage between HRD Instruments, Processes, Outcomes and Organizational Effectiveness

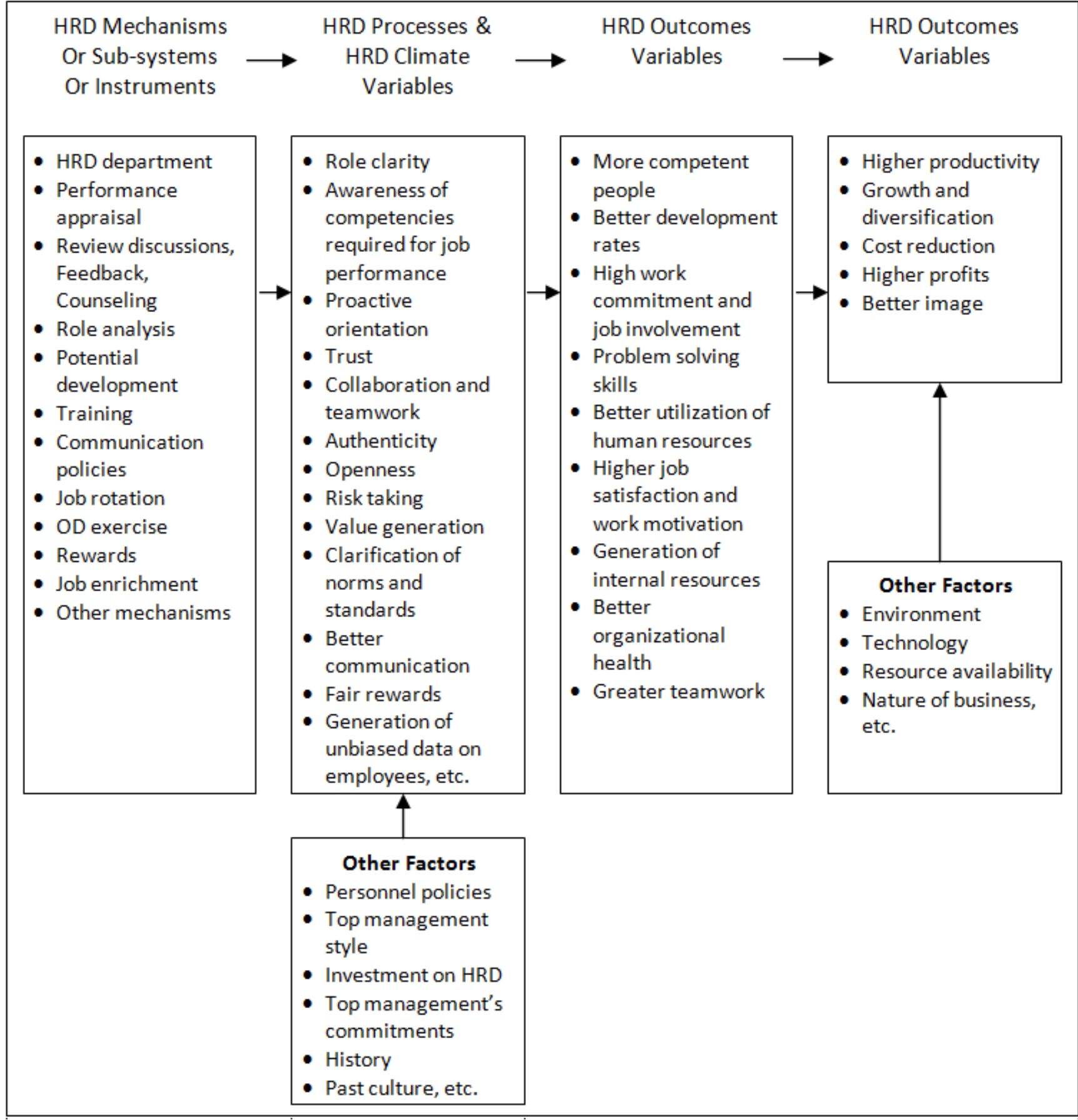

Here, the main issue is that HR mechanism should be developed since it leads to the desired outcomes. Only a HR mechanism can fulfill the basic philosophy of HRM. This could be understandable in Lawrence Kleiman Model. He states that the influence process follows a path where the mechanisms lead to outcomes (employeecentered and organizational centered), which in turn, can lead to competitive advantage. The path taken is as follows: 
Fig- 5: L Kleiman Model of HRM Practices

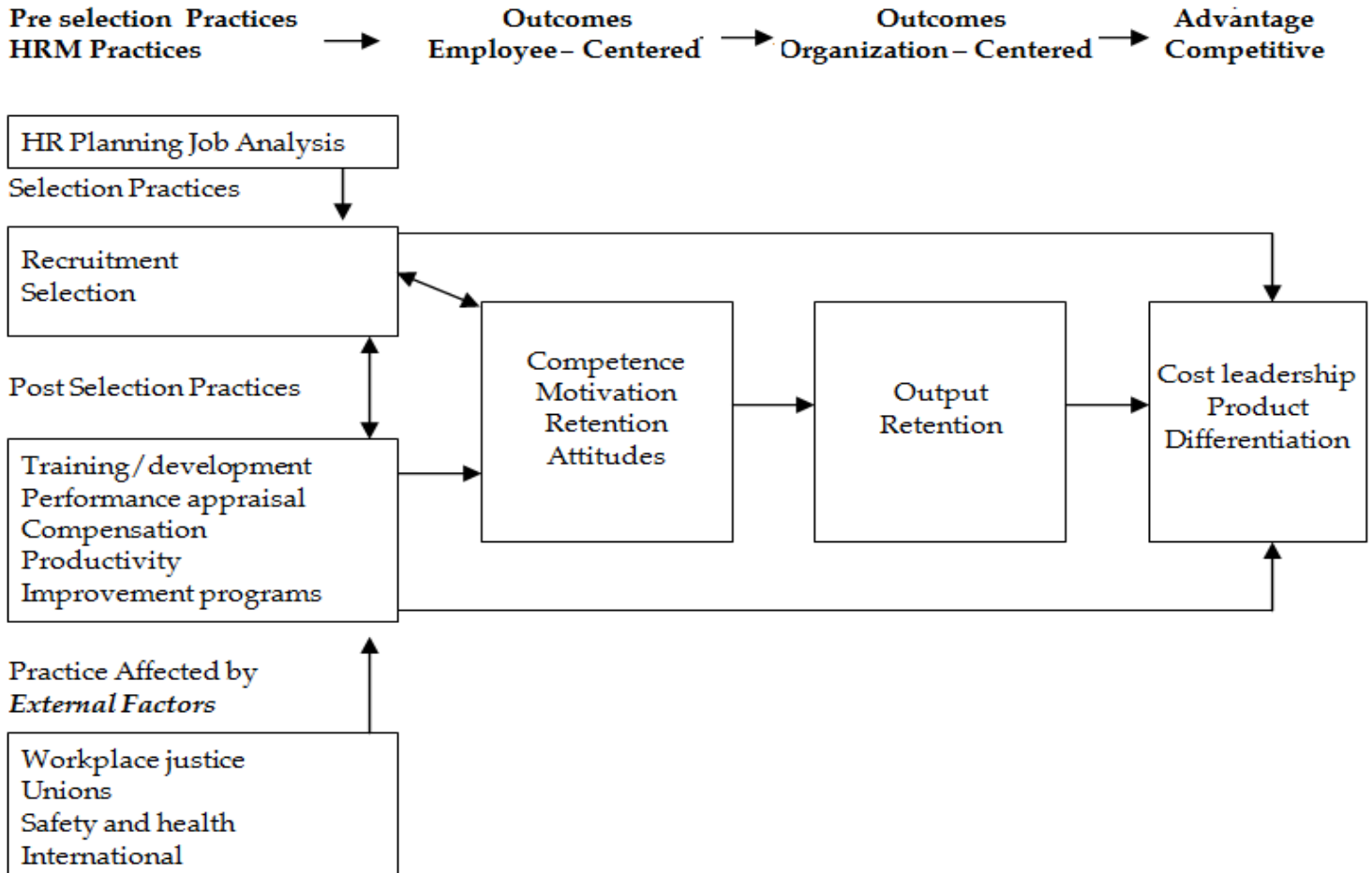

Source: Beer, et. al., Human Resource Management: A General Manager's Perspective, The Free Press, New York, 1985, p. 17.

Here the employee centered outcomes refer to the competence level of each employee, employee's willingness, and employee's attitudes such as job satisfaction level, commitment, and citizenship behavior which result from the right kind and right combinations of the instruments. On the other hand, the organizational outcomes are productivity level (in terms of quantity and quality of the product and the USP of the product), image of the company, legal compliances etc which are result of the employee level outcomes. Naturally, for example if the employees of a firm are highly satisfied and committed then they will

Fig. 6: Map of the HRM Territory

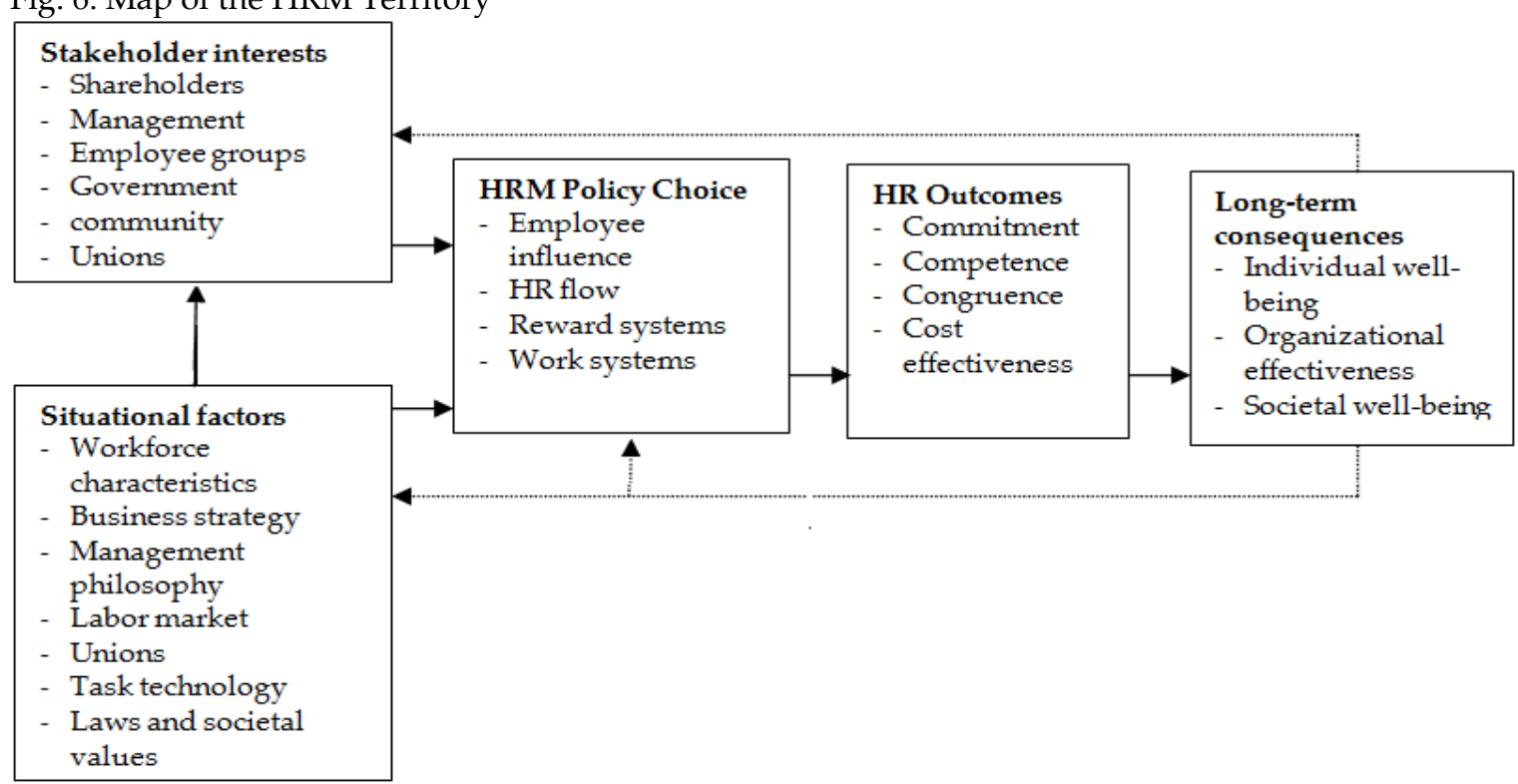

communicate a good image of the company. This level outcome will give competitive advantage to the company through the generation of its good will in the market.

\section{Key Factors Influencing HRM Policies}

There are certain key factors that have a strong influence on HRM policies and are in turn influenced by them (Ali, 2009). These factors must be taken into account while designing HRM policies. These factors are put into two major considerations: situational factors and stakeholders interests as depicted in the following figure: 
The figure shows that HRM policies are not only influenced by the factors stated above, but affect certain immediate organizational outcomes and have certain long-term consequences.

\section{Organizational EfFEctiveness}

Organizational Effectiveness is the concept of how effective of an organization is in achieving the outcomes of the organization intends to produce. In Organization Effectiveness through HRD, human resource executives can share their explored experiences in developing people. There is a positive relationship between human resource development and organization effectiveness. Joseph and Singh (2000) attempted to describe in their study that asserts competing, performing, stretching, service organizations also need to review, reflect, redirect, reorient, renew human resources in the organization through a continuous process of individual and collective development initiatives. TV Rao, HRD and Organizational Effectiveness (1990) writes that other things being the same; an organization that has competent, satisfied, committed and dynamic people is likely to do better than an organization that scores low on HRD outcome variables. In the same way, an organization that has better HRD climate and processes is likely to be more effective than an organization that does not have them. It is stressed that HRD outcome variables are step closer to organization effectiveness. Organizational Effectiveness, within the Office of Human Resources, serves as a gateway to training, development, and consulting resources that build organizational capacity, increase individual capabilities, and promote a culture of excellence through strong leadership. Organizational Effectiveness offers a variety of programs and services designed to build job skills and enhance professional development providing workshops, seminars, classes, and consulting services each year. The HRD tools if effectively used can create a conducive HRD culture and HRD learning processes. HRD processes are intermediate variables and affect the HRD outcomes. They are less easily observable and are softer dimension that indicates the effectiveness of HRD tools.

\section{FINDINGS}

In consonance with prior discussion it is appeared that the department of HRD of an organization is attentive on the following major areas:

- Increasing the 'enabling' capabilities by developing human resources, organizational health, team spirit, and increasing employment motivation and productivity.

- Focus on balanced organizational culture by conducting periodic surveys, workshops, discussions, stimulating openness, mutual trust, team spirit, creativity, initiative, mutuality, collaboration, autonomy, respect, management of mistake, management of conflicts, etc.

- Focus on learning contextual factors from different professional bodies like NIPA, BPATC, NAEM, IBA, BIBM, BIM, ISTD, HRD Network etc. These professional bodies, through their publications, seminars and workshops, share the experiences of the corporate world.

- Focus on periodic reviewing of the HRD system which may call for redesigning performance appraisal, job rotation, reward systems, career planning, promotion, selection, induction, training and development, etc.

- Focus on integrating HRD with other corporate functions like production, marketing, finance, material, corporate planning etc.

- Focus on diffusion of HRD function involving line managers in various HRD aspects like training of subordinates, performance appraisal, promotion, placement, selection, career planning, etc. line people, by virtue of their rich experiences, may effectively contribute to these HRD areas.

- Focus on working with unions by taking them into confidence and collaborating with them. That unions can also play a positive role in furthering the organization is evident from a number of examples.

In Bangladesh, some large private sector organizations have commenced establishing separate units known as human resource divisions/ department. But unfortunately, these divisions are mostly manned by generalists. In the public sector and autonomous organizations, the situation is more deplorable though they are trying to rescue from the situation.

\section{SUGGESTIONS}

Therefore, to design HRD policies, all the likely constraints due to inadequacies affecting the HR policies and the HR outcomes as well as organizational outcomes and long-term consequences must be attentive seriously in the areas of decreasing organizational outcomes that should be:

- Employees should be informed of changes in the environmental demands with their implications for wages, work practices, and competency requirements. This is responsible for the management.

- Employees with high competencies will have versatility in skills and the perspective to take on new roles and jobs as needed. They will be more capable of responding to changes.

- HR in terms, of wages, benefits, turnover, absenteeism, strikes, grievances and so on costs must be considered for organizations, employees and society as a whole.

- If HRD does not encompass the HR functions an identity should be developed. 
- When HRD at a higher level in the organizational hierarchy does not entrust the responsibility establish credibility for the HRD functions.

- While structuring the HRD department of an organization, it should be ensured that it has linkages with external and internal systems, i.e., HRD department should represent various task groups, adhoc committees, etc.

- For ensuring the industrial relations HRD department should balance between integration and differentiation that does ensured not diluting the HRD function. Integration could be achieved by diffusion of HRD function with other major corporate functions like, marketing, production, and line functions, as inputs from those areas can enrich the functioning of the HRD department.

- Organization should follow participation policies like MBO, MBE, MBD, MBF, TQM etc. with a view to obtaining stated results. They should balance between qualitative (subjective) and quantitative (objective) decisions.

- Finally, HRD systems should develop a strong feedback and re-enforcing and monitoring mechanism.

Organizations should follow basic principles governing the functioning of HRD systems in an organization developed by ASTD.

\section{Concluding Remarks}

HRD practices enhance the internal capabilities of an organization to deal with current or future challenges to be faced by an organization. HRD process variables include role clarity on a continuous basis, working planning, awareness of competencies and a more directed efforts to build them, better communication and the practice of HRD values like openness, trust, pro-active, authenticity, autonomy, confrontation etc. Such HRD culture and processes can result in more observable and quantifiable outcomes which include a higher level of competencies of the employees, better utilization of human resources through better developed roles, higher work commitment, work motivation, greater team work and synergy etc. by which the HRD outcome can influence the organization's business goals which may be in terms of higher productivity, cost reduction, more profits, better image and more satisfied customers and stake holders.

\section{FURTHER STUDY}

The success and sustainability of complexities involved modern organizations depend on focusing HR. Almost all effective organizations have become more careful for the development and utilization of their HRs in order to achieve stated goals. In such a scenario, it has become imperative for the academicians, practitioners, and professionals to explore HRM as a branch of study. Our study has been developed to help the management students and professionals to understand the subject properly and enhance their knowledge about HRD network within the organization for its effectiveness.

\section{REFERENCES}

Ahmad, S. (2007). Human resource Development in Universities. APH Publishing.

Ahmad, S. M., \& Mir, A. A. (2011). Need for Human Resource Development (HRD) Practices in Indian Universities: A key for Educational Excellence. Journal of Human Values, 18(2), 113-132.

Ahmed, A. U., Huq, S., Karim, Z., Asaduzzaman, M., Rahman, A. A., Alam, M., \& Chowdhury, R. A. (1993). Vulnerability and adaptation assessments for Bangladesh. In Vulnerability and Adaptation to Climate Change (pp. 141-159). Springer Netherlands.

Akanni, J. A. (1991) Management Concept, 3rd edition techniques and cases

Akpan, L (1981) Management in Nigeria, Lagos: Nim Magazine, Nov.

Ali, Omar, Essentials of Human Resource Management,Rajshahi University, $1^{\text {st }}$ Edition, 2009, pp.21-29.

Basu, C.R., "Human Resource Development”, Vol. XI (Jan-June 1987), Indian Journal of Commerce, P. 150-151

Beer, M. (1985). Human resource management: a general manager's perspective: text and cases (Vol. 1). Free Pr.

Bhattacharyya, D. K. (2009). Human resource planning. Excel Books India.

Bhattacharyya, D.K., Human Resource Planning, EXCEL BOOKS, Newdelhi, 2006, pp.6-24.

Billimoria, R. P., \& Singh, N. K. (1985). Human resource development: a study of the airlines in Asian countries.Vikas Publishing House Private.

Billimoria, R.P. \& Singh, N.K.: Human Resource Development, Vikas Publishing House Pvt. Ltd, New Delhi, 1985, p.3

Chowdhury, I. G (2003). "Human Resource Development: A competitive Perspective", Journal of Business Administration, IBA, University of Dhaka,p. 127.

Chowdhury, M.A (2003). "Human Resource Development and Economic Growth: A Critical Analysis with Special Reference to Bangladesh", Insurance Journal, Bangladesh insurance Academy, p.149.

Dayal, I. (1989). IHRD in Indian Organizations, "Current Perspectives and Future Issues". Vikalpa, Vol.14.

Dayal, Ishwar: HRD in Indian Organisations, "Current Perspectives and Future Issues". Vikalpa, Vol.14, OctoberDecember 1989, P. 9-15 IshwarDayal, Designing HRD Systems, New Delhi, Concept, 1993

Hijmans, R. J., Cameron, S. E., Parra, J. L., Jones, P. G., \& Jarvis, A. (2005). Very high resolution interpolated climate surfaces for global land areas. International journal of climatology, 25(15), 1965-1978.

Joseph, J., \& Singh (2000) “Organization Effectiveness through HRD" 36, no.1 Indian Journal of Industrial Relations, Oxford and IBH Publications Co. Pvt.

Khan, M.N., "HRD in Model Technological Structure", XL No:150-51 (Jan-June, 1987), Indian Journal of Commerce, p. 83

Lakshmi, C. S. (2005). Human Resource Development in Public Enterprises. Discovery Publishing House. 
Mufeed, S. A., \& Gurkoo, F. A. (2006). Enhancing educational institutions effectiveness through HRD climate: An empirical assessment. Management $\mathcal{E}$ Change, 10(2), 25-63.

Munaga, R. M., \& Kholkumbe, B. S. (2015). A study of trade unions in selected large and medium scale industries in Visakhapatanam District AP.

Nadler, L., "Defining the Field - Is it HRD or OD or" Training $\mathcal{E}$ Development Journal, 34, No.12 (December 1980), Published by ASTD, p. 66, Fransisco, 1986, p. 8.

Ogbodo C.Y. (2007) Annals of Management Accounting: An Empirical Approach, 1st edition, Awka: Rex Charles and Patrick Ltd.

Rao, T. Pareek, H. S. (1981). Readings in human resource development. Oxford and IBH Publishing

Rao, T. V., HRD Audit: Evaluating the Human Resource Function for Business Environment, Response Books, New Delhi, 1999, p. 17-18.

Rao, T. V., The HRD Missonary, Oxford IBH, New Delhi, 1990, p. 7.

Rao, T.V, Raju and Yadav, "A Study of HRD Concepts, Structure of HRD, Structure of HRD Departments and HRD Practices in India" Vol 26(1) (Jan-March 2001), Vikalpa

Rao,T.V., Reading in HRD, New Delhi, Oxford \& IBH, 1990.
Roknuzzaman, M. (2007). Status of human resource management in public university libraries in Bangladesh. The International Information $\mathcal{E}$ Library Review, 39(1), 52-61.

Sharif, TR, "Human Resource Development (HRD): In the Theory and Practice," 25 (July \& October, 1999), Journal of Business Administration, IBA, University of Dhaka, p.1

Sharma, A and Purang, P., "Value Institutionalization and HRD Climate: A Case Study of a Navratna Public Sector Organization", Vol 4 (2000), Vision, The Journal of Business Perspective, pp. 11-17.

Silveria, D.L., Human Resource Development: The Indian Experience, Newsbook Publication, New Delhi, 1987, p, 29.

Susan, M. R. (2005). Women and Leadership in Higher Education Current Realities, Challenges, and Future Directions. Advances in Developing Human Resources, 14(2), 131-139.

Susan, M. R. (2012). Women and Leadership in Higher Education Current Realities, Challenges, and Future Directions. Advances in Developing Human Resources, 14(2), 131-139.

Ubeku, A.K (1995) Personnel Management in Nigeria Benin City: Ethiopia Publishing Company.

Werner, S., Schuler, R. S., \& Jackson, S. E. (2012). Human resource management. Cengage Learning. 